\author{
Holger Rajavee
}

\title{
KAKS GEENIUST. \\ LOMAZZOST DIDEROT'NI
}

Antiikaegsed inimesed nimetasid Geeniust looduse jumalaks, kes omas kõikide asjade tekitamise väge, seepärast öeldi, et igal asjal oli oma Geenius. Inimesele omistati kaht geeniust (genii), head ja paha. See on samuti pärit loodusest enesest. Mõned arvasid, et Geenius ise ongi hing või meel (animam) või siis Jumal või vaim, mis õhutab surelikke mõnudele / ihadele (voluptatem): seepärast nimetasid antiikaegsed inimesed neid, kes hoolisid väljanägemisest ja naudinguist, geniaalseteks. Siit ka ütlus - anduma oma Geeniusele. Oli ka neid, kes pidasid vett, maad, tuld, kahtteist tähemärki, päikest ja kuud jumalike geeniuste tehtuiks. Kuna nad suutsid kanda raskeid koormaid, omades gerendo't, nimetati neid esmalt Gerulos'teks (koormakandjateks) ning hiljem Geeniusteks. ${ }^{1}$

Charles Estienne, 1553

Nii kirjeldatakse geeniust 1553. aastal teoses „Novum Dictionarium historicum ac poëticum“, mille autoriks peetakse Charles Estienne'i. ${ }^{2}$ Võib öelda, et ülaltoodud visioon on omane kogu renessansiajastule ning kestab suurel määral ka järgneval paaril sajandil. Seda eelkõige tänu mitmete antiikautorite teoste taaspublitseerimisele ning -tõlkimisele.

DOI: http://dx.doi.org/10.12697/BJAH.2016.11.04

1 Charles Estienne, Novum Dictionarium historicum ac poëticum (Paris: Charles Estienne, 1553). Genius, dicebatur à priscis deus naturae, \& qui omnium rerum gignendarum vim haberet, unde cuiusque rei dicebatur suus Genius: hominique duos genios assignabant, bonum \& malum. Accipitur pro ipsa natura. Quidam ipsam animam vel Deum, vel spiritum esse volunt qui mortales ad voluptatem incitet: vnde Geniales ab antiquis apellabantur, qui ad curandam cuticulam erant prompitores. Inde proverbium, Indulgere genio. Fuerunt etiam qui aquam, terram, ignem, aerem, item duodecim signa, \& solem \& lunam, deos genios facerent: \& a gerendo, quod multa genere possent, primum Gerulos, deinde Genios appellatos esse putarent. (Tlk Holger Rajavee).

2 DeWitt T. Starnes, „The Figure of Genius in the Renaissance“, Studies in the Renaissance, 11 (1964), 239. 


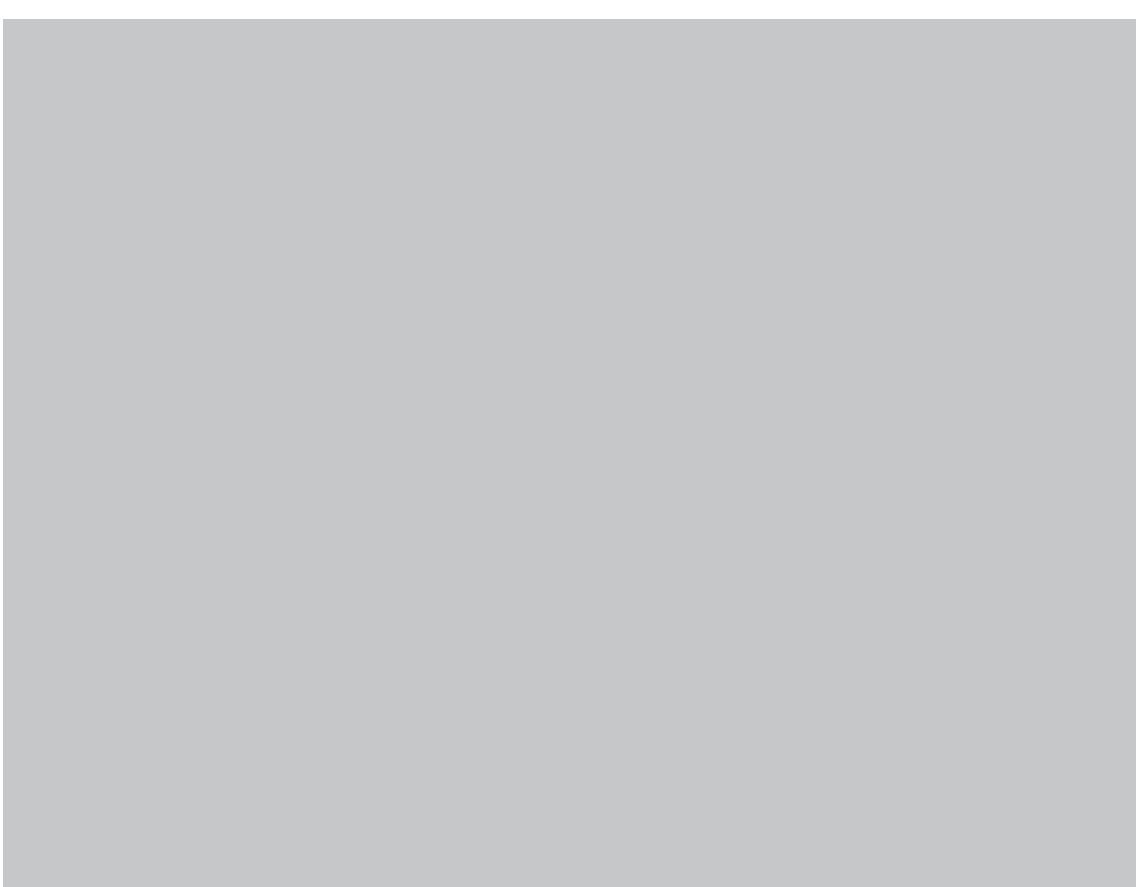

Ill. 1. Cesare Ripa, Iconologia (Venezia: Appresso

Nicolò Pezzena, 1669). Väike geenius.

Ehkki käesolev artikkel keskendub kitsamalt kunstnik-geeniuse isikule ja selle arenguloole alates 17. sajandist kuni 18. sajandi keskpaigani, s.o ajajärgule, mil toimusid kõige märkimisväärsemad muutused kunstniku kui persooni kujunemisel, väärivad mitmed edaspidi käsitletavad teemaarengud tagasipöördumist Estienne'i teosest nopitud tsitaadile, mis esmapilgul võib näida ehk juhuslikuna. Toetudes prantsuse kunstiteoreetilise ja esteetilise mõtte traditsioonile, on artikli eesmärgiks näidata, kuidas ja miks kujunesid nimetatud perioodil välja kaks erinevat kunstnikutüüpi. Lähtudes esmajoones antud ajastust pärinevatest algtekstidest, aga ka nende hilisematest tõlgendustest, kerkivad reljeefselt esile kaks oma olemuselt diametraalselt teineteisest eristatavat autorit, nimetagem neid tinglikult „õppinud geeniuseks“ ja „,hullunud geeniuseks". Mõlema algseks lähtepunktiks on ladina kultuuriruumist pärit genius (vanakreeka pärandist tulenev daimon). Kes on need kaks geeniust, mille poolest nad erinevad, mis on ühe ja teise kunstnikutüübi peamised tunnusjooned ning miks julgeb siinkirjutaja väita, et viimane neist ilmestab meie kunstinägemist tänini?
Nagu öeldud, geeniuse seletusi on mitmeid. Mõnede mõtlejate jaoks kannab geenius eneses inimmõistuse võimekust, mis on suuteline ületama materiaalse looduse piire. Teised soovivad aga geeniust, vaatamata tema kõikidele imelisena näivatele võimetele, määratleda nende piiride sees olevana. Esimeste kohaselt, on ta oma olemuselt üleloomulik ime, mis pärineb transtsendentsest jumalavallast, teise grupi jaoks on tegu inimpsüühe läbinisti loomuliku ja maise väljendusega. Noel L. Brann on selle vastuseisu taga näinud n-ö aegade hämarusest kuni tänase päevani kestvat filosoofilist dispuuti kahe maailmanägemisviisi ja -õpetuse - Platoni ja Aristotelese - vahel. Platonistid viitavad selles vaidluses geeniuse päritolule, mis kuulub igavikuliste ideede hulka ning on võimeline mitte ainult ületama looduse muutlikkust, vaid vastanduma looduslikele seaduspäradele, Jumala poolt inimmõistusele antud üleloomulike jõudude läbi. Aristoteliaanid, kes suutsid end vabastada pikaaegsest seotusest platonismiga, mis oli väldanud varakeskajast alates, peavad kinni tagasihoidlikumast seisukohast, mis ütleb, et ilmingu päritolu peitub enam selle loomulikes / looduslikes koostisosades. ${ }^{3}$

17. sajandi vältel, mil kunstiteoreetilise mõtte juhtiva rolli said kunstide akadeemiad, areneb ja kinnistub aste-astmelt „õpetatud kunstnik-geeniuse" kuvand. Gian Paolo Lomazzo ja tema 16. sajandi lõpus trükivalgust näinud teosed „Trattato dell'arte della pittura, scoltura et architettura“ (1584) ning „Idea del tempio della pittura“ (1590) sätestavad manerismi põhireeglistiku ${ }^{4}$ ja vaatlevad kunstniku tegevust kui autori vaimse mõtte ratsionaalset ning tehnilist teostust. ${ }^{5}$ Samaaegselt esindab Lomazzo uusplatonistlikku seisukohta, väites, et ideaalne ilu on kujutis, mis peegeldub kunstniku meeltes ja pärineb jumalavallast ning mitte olemasolevast loodusest. See on religioosne, müstilisust sisaldav õpetus, mis on kooskõlas vastureformatsiooni vaimuga, mitte pakkudes empiirilist täiuslikkuse väljundit nähtava (välise) looduse vormide valikus,

3 Noel L. Brann, The Debate Over the Origin of Genius During the Italian Renaissance: The Theories of Supernatural Frenzy and Natural Melancholy in Accord and in Conflict on the Treshold of the Scinetific Revolution (Leiden, Boston, Köln: Brill, 2002), 1-3.

4 Lomazzo toetub oma teostes esitatud mõtetes suurel määral Marsilio Ficino teosele „Theologia Platonica de immortalitate animae“, olles Erwin Panofski väitel Ficino uusplatonismist kantud Ilu kontseptsiooni otseselt plagieerinud. Vt Erwin Panofsky, Idea: A Concept in Art Theory (New York

Gerald M. Ackermann, Lomazzo's Teratise on Painting", The Art Bulletin, vol. 49, 4 (1967), 317. 


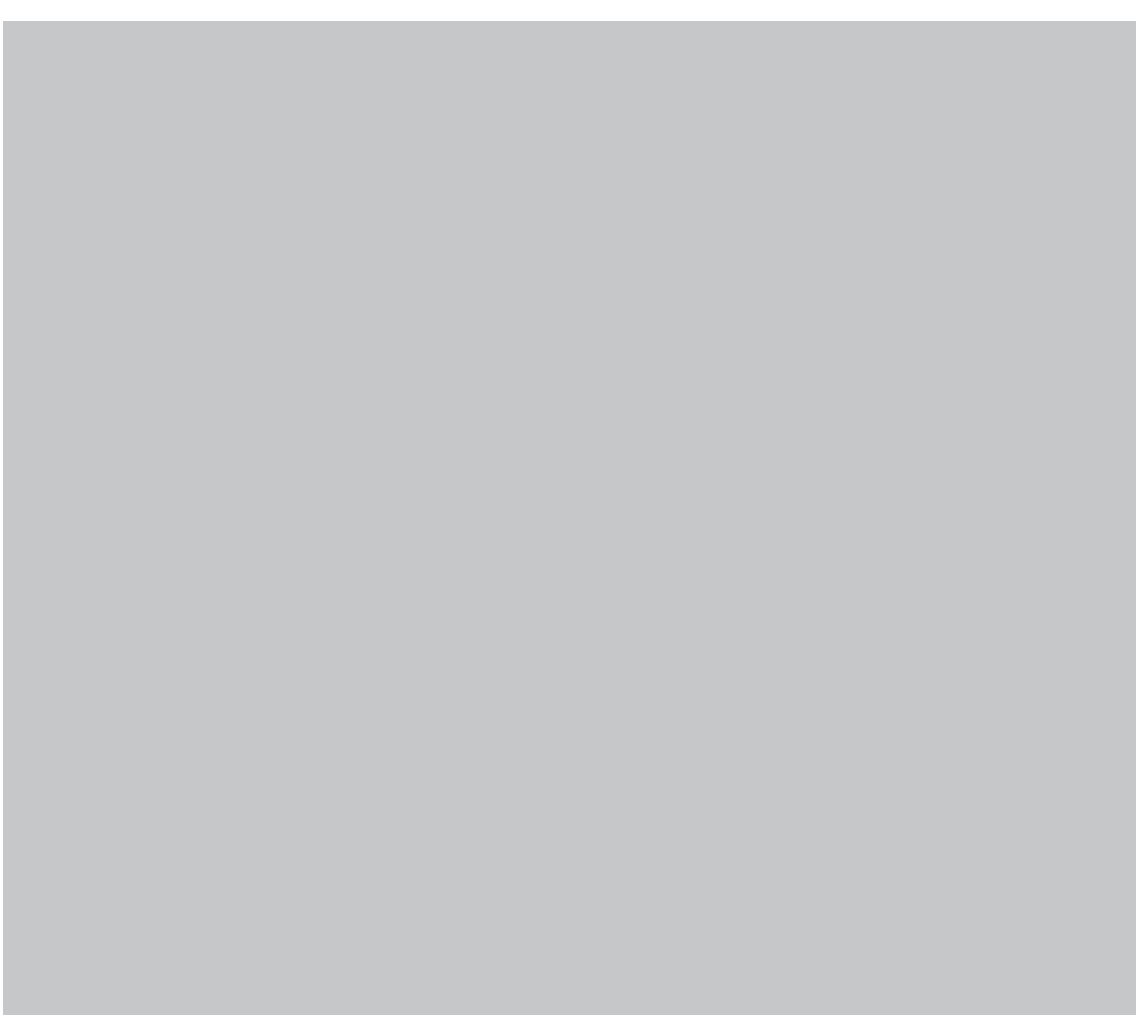

Ill. 2. Giovanni Paolo Lomazzo, Idea del tempio della pittura (Bologna: Nell'Instituto delle Scienze, 1785). Teose tiitelleht.

vaid avastades selle platonlikul moel mittemateriaalse ideena läbi sisemise ja subjektiivse kontemplatsiooni. ${ }^{6}$

Lomazzo õpetusele sarnaselt kõlavad ka tema kaasaegse Federico Zuccari seisukohad. Kujutades enesele ette ja pannes pildile „neid asju, mis pole nähtavad“ on Zuccari müstik, „keda aidatakse tõusta võime juurde kontempleerida pühade asjade üle“. Samastades oma „sisemise kujutise" (disegno interno), mis ei kanna eneses vähimatki ainelist alget, müstikute terminiga „meie sees hõõguva pühaduse sädemega“ (scintilla ardente della divinita in noi), on see tervikliku jumalikkuse peegelduseks kunstnikus eneses. ${ }^{7}$ Rõhutamaks seda, kasutab ta kujundlikku

6 Rensselaer W. Lee, „Ut Pictura Poesis: The Humanistic Theory of Painting”, The Art Bulletin, vol. 22,4 (1940), 207.

7 Federico Zuccari, L'idea de pittori, scultori ed architetti (Roma: Nella stamperia di Marco Pagliarini, 1768), 8-9. sõnamängu - disegno kui segno di Dio (di-segn-o) - „Jumala märk“, lisades seeläbi „märgi“ teostajale kõrgema lisaväärtuse. Nii Lomazzo kui Zuccari õpetuses võib näha eemaldumist renessansiajastule omasest humanismi mõttemaailmast ning manerismile omast tagasipöördumist keskaegse katoliikliku teoloogia ja gootika suunas. . Samas „raamistavad“ mõlemad kunstniku tegevusvälja manerismile omase kunstikaanoni selgepiirilisusesse - kujutatava ideaalne, akadeemiline vormikeel hakkab tähendama kunstniku eneseväljendust suurte ja ,jumalike“ endisaegsete meistrite tundmaõppimise kaudu.

1648. aastal asutatud Prantsuse Kaunite Kunstide Akadeemia saavutas mõne kümnendi vältel tooniandvaima positsiooni kogu Euroopa kunstiteoreetilise mõtte arengus. On sümptomaatiline, et sajandi lõpul aset leidnud vaidluses $n$-ö vana ja uuemeelsete vahel (Querelle des anciens et des modernes) jääb peale konservatiivsem leer, mis jätkab antiigipärandile tugineva klassikalise traditsiooni vaimus. Võib väita, et vaatamata sellele, et teadusliku mõtlemise vallas tõrjuvad modernistid vanameelsed tahaplaanile, jäävad viimased kunsti puudutavates küsimustes eelisseisu. ${ }^{9}$ Silmas pidades sajandi üldist vaimset ebakindlust, mida tekitas kestev ja kompromissitu kirikulõhe katoliiklike ja reformatsioonikirikute vahel, on antiikkultuuri tagasivaatav hoiak ilmseks mentaalse turvalisuse garantiiks. Viimane omakorda kinnistas veelgi vajadust „õpetatud geeniuse“ järele. Klassikaline doktriin (doctrine classique) rajaneb veendumusel, et mõistus on nii kunstilise loome kui ratsionaalse reflektsiooni peamiseks töövahendiks. ${ }^{10}$

„Teadmine arendab ja täiustab geeniust, paljastades ja taltsutades hullust kunstis. Mõõdukus kõikides asjades peitub piiripidamises / reeglites, mis ei lase upsakusel esile kerkida", väidab oma luuletraktaadis „De Arte Graphica“ (1668) Charles Alphonse du Fresnoy. ${ }^{11}$ Geeniuse ülesandeks on lähtuda küll loodusvormidest, ometi on oluline tõusta neist aste-astmelt kõrgemale, leida endas üles nn „õpetatud geenius“.

8 Anthony Blunt, Artistic Theory in Italy 1450-1600 (Oxford: Oxford University Press, 1994), 143. 9 Art in Theory, ed. by Charles Harrison, Paul Wood, Jason Gaiger (Oxford: Blackwell Publishing, 2000), 16.

10 Ibidem.

1 Charles Alphonse du Fresnoy, De Arte Gaphica / The Art of Painting (London: J. Heptinstall, 695), 10

Indolis excolitur, Geniumque scientia complet,

Luxuriansque in monstra furor compescitur Arte:

Quos ultra citraque nequit consistere fines, 


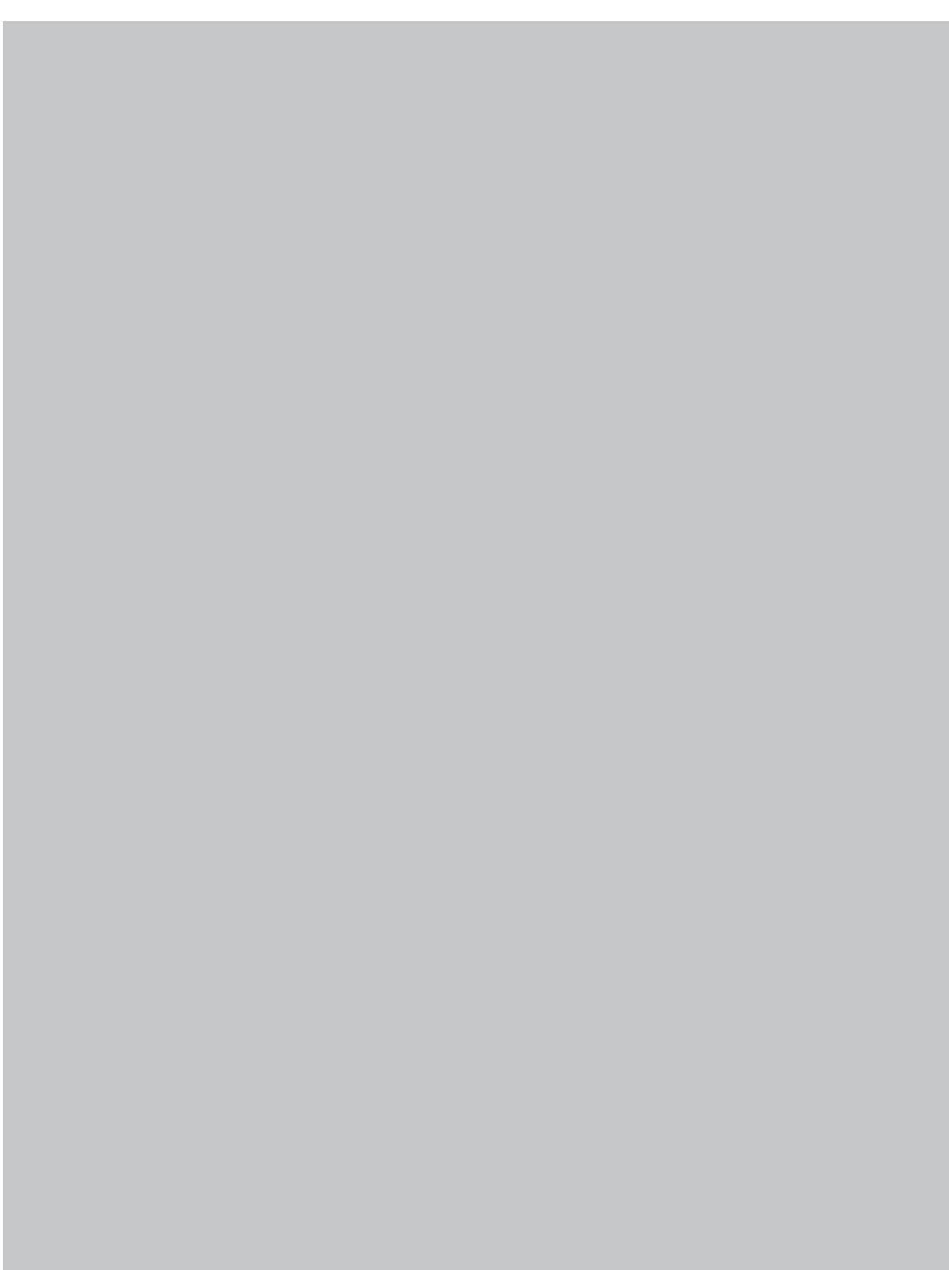

IIl. 3. Charles Alphonse du Fresnoy, De Arte Gaphica / The Art of Painting (London: J. Heptinstall 1695). Minerva ja Maalikunst.

Du Fresnoy järgi on kunstnikule oluline (vajalik) „,otsustusvõime, õpetatud anne, õilis süda, ülev tunne, terve keha, õitsev nooruslikkus, asjalik meel, töökus, kunstiarmastus ja õpetatud meistri käe all saadud oskused.“12 Seejuures möönab autor, et kui inimeses puudub geenius või loomulik ",kalduvus“ (Ni genius quidam ad fuerit Sydus que benignum), ei ole võimalik saavutada sel alal täiust, kuna „, ande ja käelise tegevuse vahel on suur vahe" (Distat ab Ingenio longe Manus). ${ }^{13}$ Mida enam kahaneb kunstnikus „müstiline“ ja ",salapärane“" geenius koos sellega kaasneva „hullusega“ (mida pigem tekitab temas "kuri geenius“ - genius malus), seda enam kerkib esile „inimlik geenius“, kelle peamiseks instrumendiks on sünnipärane anne (talent). ${ }^{14}$

Ilu ideel baseeruva klassitsismi doktriini üheks olulisemaks autoriks on Giovanni Pietro Bellori. Kuulutades ainelise looduse kunstniku täiuslikkuse kontseptsiooni jäljendamisallikaks, tõstab Bellori esile Aristotelesest lähtuva poeetika traditsiooni, mis oli juba varem leidnud koha kirjandusteoorias. ${ }^{15}$ Oma arutluse „Vite dei pittori, sculttori et architetti moderni“ (1672) proloogis kirjeldab Bellori ideed kui kunstniku meeltes olevat "ülima ilu näidet“ (esempio de bellezza superiore). Täiuslikud detailid (cause esemplari), mille järgi tehakse kunstiteosed, asuvad kunstnike meeltes ja kannavad eneses igavese ilu täiust. Astudes esile uusplatonistina, kes ajastu vaimus retooriliselt kõlava sissejuhatuse järgi, võtab omaks aristotelliku seisukoha, mis seostab idee looduse algupärase võimu / natuuriga (originata della natura), defineerides seda kui loodusliku ilu täiust (il perfetto della bellezza naturale). Kogu arutluse vältel ei jäta ta lugejale mingit kahtlust selles, et ta ei vaatle ideed kui arhetüüpset ilu, mis eksisteerib aprioorselt metafüüsiliselt sõltumatuna, vaid esmalt millenagi, mis on tuletatud kunstniku valikulise tegevuse kaudu olemasoleva looduse kogemisest. Veelgi enam - läbi valikulise kunstitõe kuulutab idee oma ülemuslikkust tegeliku loodusetõe suh-

12 Du Fresnoy, De Arte Gaphica / The Art of Painting, 69.

Judicium, docile Ingenium, Cor nobile, Sensus

Sublimes, firmum Corpus, florensque Juventa,

Commoda Res, 13 Ibidem.

14 On oluline vahet teha mõistete „geenius“ ja „talent“ vahel. 17. sajandi lõpus võib kaht terminit vaadelda kui sünonüüme - Le Dictionnaire de l'Académie françoise (1694): „See tähendab ka loomulikk kalduvust vơi săttumust või igaühe erilist talenti. " Il signifie aussi, L inclination ou disposition naturelle, ou le talent particulier dunchacun). Muttus toirm juba postuleer vastanduvad teineteisele. Talendi puhul on tegu ükskōik millise intellektuaalse jôuga. Geeniuse puhul on aga tegu palju harvemini esineva vaega, mis pärineb otse loodusest, kantavast ja nautiva vaimust, naudingu ja valu vaimust."

Siin ja edaspidi on prantsuskeelsed tsitaadid tôlkinud Mirjam Lepikult, kellele siinkirjutaja on lahke

15 Lee, Ut Pictura Poesis: The Humanistic Theory of Painting", 208. 
tes, ehkki ta pärineb otseselt sellest (originata della natura, supera l'origine, e fassi originale dell'Arte). Huvi looduse / natuuri kui ideaalsete kontseptsioonide allika vastu, on Bellori puhul kesksel kohal, peegeldades empiirilis-idealistlikku vaatepunkti, mis iseloomustab 17. sajandi barokiajastut tervikuna, nii nagu irratsionaalne Platoni õpetus oli iseloomulik manerismiajastule. ${ }^{16}$ Bellorit võib vaieldamatult nimetada üheks esimeseks 17. sajandi autoriks, kes formuleerib klassitsismi peamise „kauni looduse" (la belle nature) doktriini. Bellori nimetab "maalikunsti inimtegevuse avalduseks, mille talletajaks on kunstnik“ (che essendo la Pittura rappresentatione d'humana attione, deve inseme il Pittore ritenere nella mente). ${ }^{17}$

Tulles aga vahetult kunstniku isiku juurde, siis piisab, kui lugeda Bellori teosest nopitud lõiku, milles ta kirjeldab Nicolas Poussini kunstnikutüüpi, mis peaks andma meile ammendava portree ,ideaalsest" kunstnik-geeniusest: „Olles paljulugenud ja teravalt tähelepanelik, ei olnud olemas teemat, milles ta oleks olnud väheteadlik. Tema sõnad ja mõtted, mis olid nii asjakohased ja selgesõnalised, ei jätnud kunagi improviseeritud muljet, pigem olid need sündinud pikaldase mõttetegevuse tulemusel. Selle kõige eelduseks oli tema ainukordne talent, millele lisandus tema laialdane lugemus, mille puhul olid eelistatud ajalugu, jutustused õpetatud teostest, mis käsitlesid teisi vabasid kunste ja filosoofiat. Tema ladina keele oskus teenis teda hästi, samuti oli hea tema itaalia keel, kuna ta oli ise pärit Itaaliast. Tema arutlused olid läbinägelikud, tema tehtavad valikud terased, tema mälu aga kindel: seepärast ta omas mõistuse kõige kõrgeimaid ande." ${ }^{\text {18 }}$

Siin ei leia lugeja jälgegi terribilità'st, millest räägib Giorgio Vasari oma lemmiku Michelangelo kohta Vite's veel sajand varem, ega ka Lomazzo kunstnik-müstikust, kes ammutab oma teoste idee jumalikust ideest. Poussinis näib puuduvat igasugune furor (olgu see siis divinus või poeticus) - see on harmooniliselt tasakaalustatud, mõistusele rajanev geenius. Kõik kunstniku poolt kunstiteoses kujutatu peab olema väärikas (it convene-

16 Lee, „Ut Pictura Poesis: The Humanistic Theory of Painting”, 209.

17 Giovanni Pietro Bellori, Vite dei pittori, scultori ed architetti moderni (Roma: Pietro Bellori, 1672), 9. 18 Ibidem, 179

Havendo egli molto letto ed osservato, non accadeva cosa alcuna nel parlare, alla quale non avesse soddisfatto, ed erano le sue parole, e i suoi concetti cosi propri ed ordinati, che non all' improvviso, ma con istudio parevano meditati. Della qual cosa erano cagione il suo buon genio, e la varia lettura, non dico delle istorie, delle favole e delle erudizioni sole, nelle quali prevaleva, ma delle altre arti liberali della filosofia. Al quale effetto gli serviva la reminiscenza della lingua latina, benché imperfettamente, sapeva cosi benel italiana come se fosse nell' Italia nato. Era perspicace nel' intendere, scelto nell'eleggere,
riten nel conservare a mente, che sono i piu desiderabili doni dell' ingegno. volezza, pr bienseance), olgu siis tegu erineva vanuse, soo või inimtüübiga, peegeldudes nii žestides, näoilmetes kui ka vastavas riietuses jne. Võib öelda, et nii nagu kujunevad välja „tüüpkujutised“ pildipinnal, nii võib rääkida ka „,ideaalsest tüüpkunstnikust“, kes järgides talle ette antud reegleid, annab teadlikult eelistuse kõrgele žanrile, väljendugu see siis žanrikategooriates (näiteks ajaloomaal) või üldiseks kaanoniks kujunenud antiigi eeskujude kasutamises. Kogu toonast akadeemia seinte vahele koondunud liikumist võiks võtta kokku sõnadega "geeniuse taltsutamine ${ }^{\prime 19}$, mille käigus spontaanne loominguline alge asendatakse reeglite ja neid toetavate meetoditega.

17. sajandi kunstiteoreetiline mõte formeerib, toetudes kindlapiirilisele reeglistikule, pildi (maali)kunstnikust kui eriliste võimete kogumit omavast, teistest käsitööliikidest lahusseisvast ja unikaalsest subjektist, kelle tegevuse läbi sünnib kunstitõde sisaldav didaktiline teos. Sellest ajajärgust alates ei seata enam kahtluse alla kunstnikku kui autorit. Kaines ratsionaalsuses tuuakse kunstnik olemuslikult tervikuna „maa peale", minimiseerides müstilist seotust ja asendades selle ainelise ilutäiuse otsinguga. Võib väita, et autori maisuse saavutamine, temasse asetatud geeniuse kaudu, loob selle vajaliku kindlustunde ja platvormi, mis võimaldab järgmistel teoreetikutel asuda tugevasse vastasseisu "õpetatud geeniuse" arhetüübiga, tõstes taas korra esile kunstniku kui unikaalse looja printsiibi.

II

Pole võimalik nimetada üht konkreetset autorit või esmateost, millest alates hakkab muutuma kunstnik-geeniuse kuvand, liikudes õpetatud geeniusest hullumeelse geeniuse suunas. Oluliseks teetähiseks sellel pikal enesetunnetuse teel on prantsuse ajaloolase ja literaadi Jean-Baptiste Du Bos' 1719. aastal ilmunud teos „Reflexions critiques sur la poësie et sur la peinture“", milles luule- ja maalikunsti võrdlemisest innustunud autor tõstab kunsti intellektuaalse külje kõrval esile selle emotsionaalse poole. „Kuna reaalsetel ja tõelistel tundmustel, mis pakuvad hingele kõige eredamaid aistinguid, on niivõrd ebameeldivad tagajärjed, sest

19 Lomazzo märgib vajadust, ,järgida oma geeniust" ning vältida liigset teiste jäljendamist, kuid samas peab geenius olema ,tasakaalustatud môistuse ja õpetatuse“ poolt. Du Fresnoy käsitleb reegleid kui vaba geeniuse ohjajaid: normarum numero immani Geniumque moretur. Du Fresnoy, De Arte Gaphica / The Art of Painting, 6. 


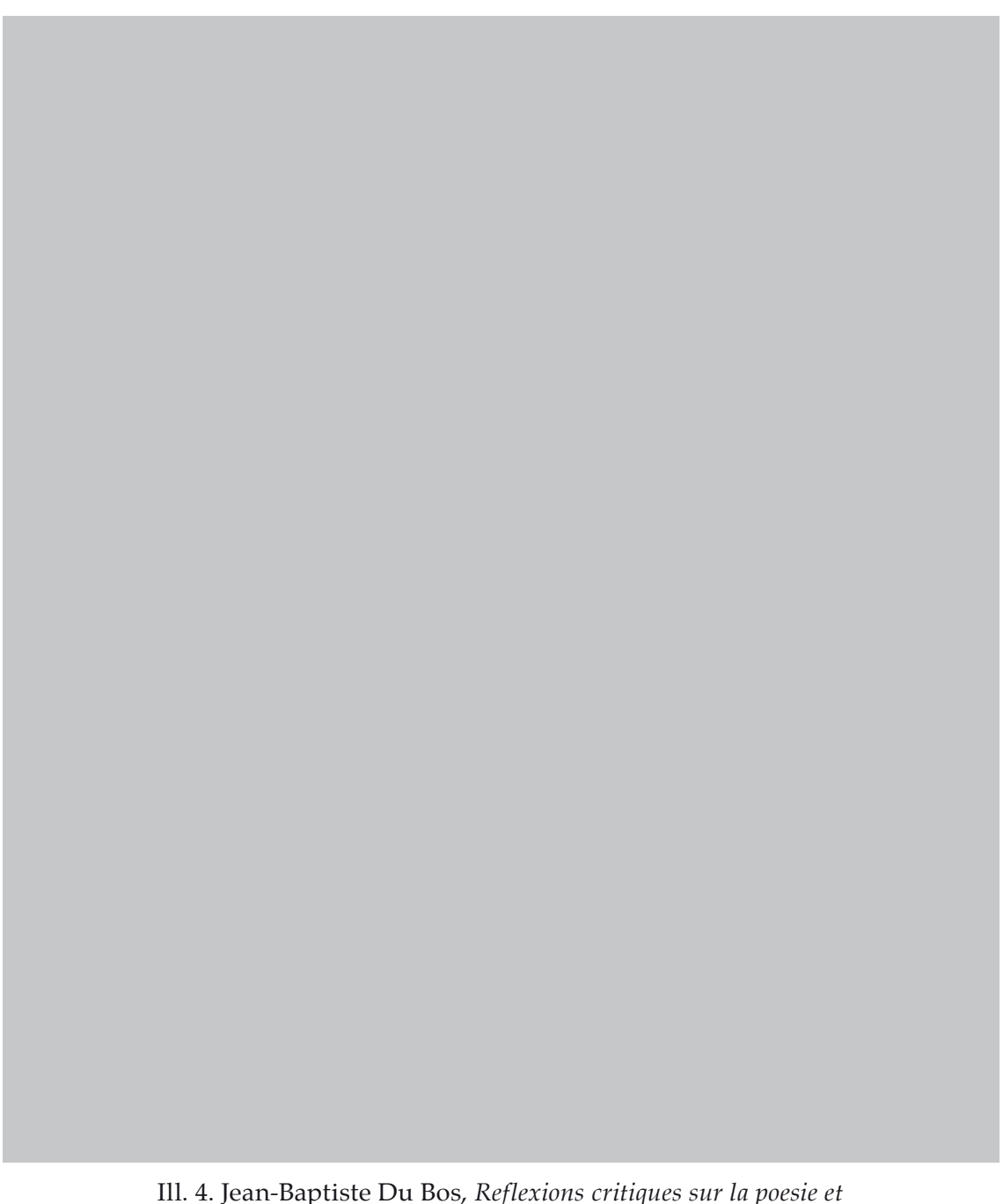

sur la peinture (Paris: Chez Jean Mariette, 1719). Teose tiitelleht.

vähestele õnnehetkedele, mida need pakuvad, järgneb terve rida kurbi päevi - kas ei võiks siis kunst leida vahendi, mis aitaks ära hoida paljude meie kirgedega kaasnevaid masendavaid tagajärgi ja samas säilitada naudingu, mida need meile pakuvad? Kas ei võiks kunst luua nii-öelda uue loomusega olevusi? Kas ei võiks kunst valmistada esemeid, mis ergutaksid meis kunstilisi tundmusi, mis suudaksid vallata meid hetkel, mil neid tajume, kuid ei tekitaks hiljem reaalseid piinu ja tõelist ahastust? Luule- ja maalikunst on selleni jõudnud“. ${ }^{20}$

Peagi tõlgiti Du Boś teos nii inglise kui saksa keelde, mis mõjutas tundeerksa romantilise kangelase ja nn "hullunud geeniuse“ levimist ainevaldkonnas. Du Bos' käsitluses on kunstnik eelkõige isiklikest tunnetest küllastunud autor. Mitte kunagi varem ei ole „kunstilise tõe“ ja „kunstiliste tunnete“ temaatika olnud esile tõstetud sellisel moel. Du Bos eemaldub „mõistusele“ toetuvast kunstilisest kogemisest, rajades oma arutluse autorikesksusest lähtuvale tundekogemisele kui peamisele (ainsale) kriteeriumile, mis tagab kunstiteose kvaliteedi ja selle valmistaja suuruse: „Maalimise kunst on nii keeruline, kuna ta ründab meid selle meele kaudu, millel on meie hinge üle nii suur võim, et pilt võib meile meeldida ainuüksi oma võluva teostuse poolest, sõltumata objektist, mida sellel kujutatakse; kuid, nagu ma olen juba öelnud, kuulub meie tähelepanu ja austus sel juhul ainult jäljendaja oskusele, kes mõistab meile meele järele olla isegi ilma, et ta meid tõeliselt liigutaks. Me imetleme pintslit, mis on suutnud loodust nii hästi matkida.."21

Selles, et geeniuseks saab vaid sünnipärasel moel, ei jäta autor lugejale mingit kahtlust, rõhutades seda nii otseselt kui kaudselt. Tegu on n-ö luust ja lihast subjektiga, kes omab erakordset sättumust läbi sünnipära. ${ }^{22}$ Autor esitab kirjelduse inimfüsioloogia kaudu defineeritud geeniusest: „Minu arusaama kohaselt seisneb nende kunstide [maalikunsti ja luule] geenius ajuelundite edukas koostöös, iga säärase elundi heas seadistuses ja samuti vere kvaliteedis, mis toimingu ajal tekitab käärimise,

20 Jean-Baptiste Du Bos, Reflexions critiques sur la poësie et sur la peinture (Paris: Chez Pissot, qua de Conti, à la Sagesse, 1755), 24.

Quand les passions réelles év véritables qui procurent à l'ame ses sensations les plus vives, ont des retour si sâcheux, parce que les momens heureux dont elles sont jouir, sont suivis de journées si tristes, l'art ne pourroit-il pas trouver le moyen de séparer les mauvaises suites de la plupart des paissions d'avec ce qu'elles ont d'agréable? L'art ne pourroit-il pas créer, pour ainsi dire, des êtres d'une nouvelle nature? Ne pourroit-il pas produire des objets qui excitasseint en nous des passions artisicielles capables de nou occuper dans le moment que nous les sentons, reelles o des affictions weritables?

La Poète e la Peinture en viennent à bout.

Du Bos, Reflexions crinques sur la poësie et sur la peinture, 66

L'art de la Peinture est si difficile, il nous attaque par un sens, dont l'empire sur notre ame est si grand, qu'un tableau peut plaire par les seuls charmes de l'xécution, indépendamment de l'objet qu'il représente. mais je l'ai deja dit, notre attention es notre estime sont alors uniquement pour l'art de l' 'mitateur qui sçail nous plaire, méme sans nous toucher. Nous admirons le pinceau qui a sçu contresaire si bien la nature. 22 Antud kusinust putdutavaid arusaamu kasitleb oma artikis Willem ". van Helsdingen „Body and soul in French art theory of the seventeenth century after Descartes", Simiolus: Netherlands Quarterly for the History of Art, vol. 11, 1 (1980), 14-22. 
pakkudes nõnda külluslikult [animaalseid] vaime neile allikatele, mis teenivad kujutlusvõime funktsioone. Äärmuslik väsimus ja kurnatus, mille toob kaasa pikaajaline vaimne pingutus, annab tõepoolest tunnistust sellest, et kujutlusvõime töö kulutab ohtralt keha jõudusid. Ma oletan, et loometöö kuumutab verd, sest maalikunstnikud ja luuletajad ei suuda midagi külmavereliselt välja mõelda; on ju teada, et oma ideid haududes haarab neid teatud eriline vaimustus. Aristoteles räägib isegi ühest luuletajast, kellel õnnestus loometöö alati kõige paremini just siis, kui tema luuleind paisus pööraseks hulluseks. ${ }^{\text {“23 }}$

Seejuures ei ole Du Bos’́ geeniuse puhul tegemist Lomazzo või Zuccari manerismiajastu kunstnik-müstikuga, kes teostab oma kunsti jumalikuga pidevas ühenduses olevana, vaid looduse poolt erakordse sisemaailmaga sündinud isikuga, kelle enese seest saavad alguse ideed ja kes need ka täide viib. Siin ilmnevad John Locke'i ja Joseph Addisoni mõjud Du Bos' käsitlusele. Viimane tugines oma teoorias ühelt poolt Locke'i väitele tunnetusliku kogemuse eelisseisundist ning teisalt Addisoni seisukohale silmast kui esmasest ja tähtsaimast tundeaistingu vastuvõtvast elundist. Võib väita, et Locke'i epistemoloogia kaudu, kes ise põlgab ära igasuguse kunstidesse puutuvate küsimuste käsitlemise oma teostes, paneb Du Bos oma teosega alguse ühele esimesele ulatuslikumale esteetikakäsitlusele. ${ }^{24}$ Toetudes ülaltoodud tsitaadis Aristotelesele, (taas) avastab ta 17. sajandil varjus olnud furor poeticus'e, mis nüüd omandab võtmetähtsuse nii geeniuse kui tema ideede näol. „Inimesel peab olema kaasasündinud geenius, et osata leiutada; kuid selleks, et hakata hästi leiutama, tuleb kaua õppida ja harjutada.. ${ }^{\prime 25}$

23 Du Bos, Reflexions critiques sur la poësie et sur la peinture. Ut pictura poesis (Paris: Chez Jean 23 Du Bos, Reflexions critiques sur la poësie et sur la peinture. Ut

Mariette, rue Saint tacques, aux Colonnes de Je conçois que le génie de leurs Arts consiste en un arrangement heureux des organes du cerveau, dan la bonne conformation de chacun de ces organes, comme dans la qualité du sang, laquelle le dispose a fermenter durant le travail, de maniere qu il fournisse en abondance des esprits aux ressorts qui serven aux fonctions de limagination. En effet lextreme lassitude \& le puisement qui suivent une longue contention desprit rendent sensible que les travaux d imagination font une grande dissipation des forces du corps. F ai suppose que le sang de celuy qui compose sechauffat; car les Peintres ev les Poetes ne peuvent inventer de sang groid. on sçaic bien quills entrent en une espece denthousiasme, lorsqu ils produisent leurs idées. Aristote parle même d' un Poète qui ne composoit jamais mieux, que lorsque sa fureur poetique alloit jusques à la phrenesie.

24 Olen nimetanud Du Bos’ teost esimeseks esteetika-alaseks käsitluseks, jättes teadlikult kõrvale ean-Pierre de Crousaz' „Traktaadi Ilust“ (Traité du Beau, 1714), kuna viimase puhul ei saa kõnel veel selgepiiriliselt valjakujundatud programmilisusest, mis aga on väljaloetav esimese puhul. 5 Du Bos, Reflexions cillques sir la poesie et sur la peinture. Ut pictura poesis, 4.

Or il faut etre ne avec du genie, pour inventer, \& l'on ne parvient meme qu'a l'aide d'une longue etude a bien inventer.
„Maalikunstniku ja Luuletaja taotluse järgi meie meeli liigutada suutvate ideede ja kujutiste leiutamise järgi tehakse vahet suurel Kunstnikul ja lihtsal käsitöölisel, olgugi, et viimased võivad tihtipeale olla teostuse asjus esimestest osavamad töölised. Parimad värsisepad ei ole suurimad luuletajad, just nagu ka kõige reeglitruumad joonistajad ei ole suurimad maalikunstnikud. ${ }^{26}$

Maalikunsti ja poeesia võrdluses, mis antiikautorite (Horatius jt) eeskujul jättis „Ut pictura poesis“ sügava jälje 18. sajandi vaimukultuur ning lubas „luuletaja, ajaloolase või erudiidi keebi maalikunstniku süütutele õlgadele ${ }^{\prime 27}$, asub Du Bos ajastul suhteliselt harvaesinevana maalikunstnike selja taha. „Ma usun, et maalikunstil on inimeste üle rohkem võimu kui luulel, ning põhjendan oma aimust kahe asjaoluga. Esiteks mõjutab maal meid nägemismeele kaudu. Teiseks ei kasuta maalikunst kunstlikke märke, nagu teeb luulekunst, vaid loomulikke märke. Just nende abil ta jäljendabki. Maalikunst kasutab silmi, et meie

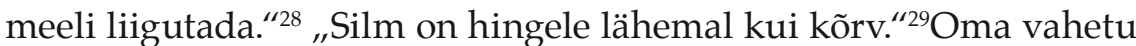
suhtumisega natuuri on maalikunst loodusele lähemal kui teadus või filosoofia (viimase kaudu ka poeesia), mis peegeldavad maailma mitte otse, vaid kaudselt. On koguni väidetud, et sel ajal, mil luulelt oodat grammatilist korrektsust, täpsust ja proosale omast selgust, mille puhul domineerisid kartesiaanlikud ideed terve mõistuse poolt korrastatud mõtlemisest, oli luulevaim "surnud“. ${ }^{30}$

Oma vaimult ja kultuurikoodilt on valgustusaeg täis sageli ületamatuks jäävaid vastuolusid. Ajastu peamiseks märksõnaks olev mõistus peidab oma sügavustes ületamatuid karisid, mis klassikalise ideaali ristlainetes viitavad isiku sügavamale hingelisele poolele. Olgu öeldud, et käsitletava ajajärgu kirjanduses tehakse selgepiirilist terminoloogilist

$26 \quad$ Du Bos, Reflexions critiques sur la poesie et sur la peinture. Ut pictura poesis, 3.

C'est a i'intention du Peintre ou du Poëte: c'est a l' ivention des idees \& des images propres a nous emouvoir qu'on distingue le grand Artisan du simple manoeuvre, qui fouvent est plus habile ouvrier que luy dan l'execution. Les plus grands Versificaeurs ne sont pas les plus grands Poëtes, comme les Dessinateur lea plus Reguliers ne sont pas les plus grand Peintres.

27 Lee, „Ut Pictura Poesis: The Humanistic Theory of Painting”, 241.

28 Du Bos, Reflexions critiques sur la poesie et sur la peinture. Ut pictura poesis, 375

Je crois que le'pouvoir de la peinture est plus grand sur les hommes que celui de la poësie, \& j'appuie mon sentiment sur deux raisons. La premiere est que la peinture agit sur nous par le sens de la vuë. La secondee est que la peinture n'employe pas des signes artificels ainsi que la fait la poesie, mais bien des signes naturels. C'est avec des signes naturels que la painture fait ses inimtations. La peinture se ser de l'oeil pour nous emouvoir

29 Ibidem, 376

L'oeil est plus pres de l'ame que l'oreille.

30 Rémy G. Saisselin, „Ut Pictura Poesis: DuBos to Diderot”, The Journal of Aesthetics and Art Criticism, vol. 20, 2 (1961), 150. 
vahet kahe ja teineteisest põhimõtteliselt erineva "geeniuse“ sõnakasutuse vahel: avoir de genie („,omada geeniust“) ning être un genie (,olla geenius"), mis on inimeses eneses orgaaniliselt olemasolev jõud ja mis omakorda näitab sellise isiku erakordsust, unikaalsust. ${ }^{31}$

18. sajandi keskpaigas kaldus vaekauss tunnete ja mõistuse vahel üha enam ratsionaalse mõistuse poole. Nagu 1746. aastal kirjutas Etienne Bonnot de Condillac, et me mitte ei loo ideid, vaid ainult kombineerime, võttes selleks abiks oma meelte kaudu saadud kujutluspildid, neid kokku pannes ja lahti võttes. Leiutamine tähendab oskust luua uusi kombinatsioone. Tehes vahet andeka inimese ja geeniuse vahel, on esimese ideed etteaimatavad, geenius aga on suuteline leiutama täiesti uut kunsti ja uut väljenduslaadi. Üksnes geenius on võimeline avastama uusi tõdesid ja heitma valgust seni hämaruses olnud asjadele. Nimetades geeniusi küll otsesõnu „loojateks“, vabandab ta nende ees: „Andku geeniused ja loojad mulle andeks, aga kogu nende teene piirdub vaatlemise, leidmise ja jäljendamisega. Leiutamine käib ainult vaadeldes ja jäljendades.“32

Condillaci mõtted kunsti ja selle looja kohta andsid tõuke uuele entsüklopedistide põlvkonnale: Rousseau, Diderot, Jean Le Rond d'Alembert. Sensualismi traditsioon sulab kokku Descartes'i vaimus mõistuse kultusega, mis näeb kogu maailma kujutlusvõime sünnitisena, andes d’Alembert' ile alust väita: „Poeesia, mis tuleb pärast maalikunsti ja skulptuuri ning kasutab jäljendamiseks vaid sobilikke sõnu, järgides kõrvale meeldivat harmooniat, kõnetab pigem kujutlusvõimet kui meeli. Ta esitab kujutlusvõimele elaval ja liigutaval kombel igasuguseid selle ilma asju ning näib neid pigem loovat kui maalivat - tänu soojusele, liikumisele ja elule, mida ta oskab neile anda.“33 Kunst näib loovat enam kui jäljendavat, kuid tegemist on siiski vaid illusiooniga. Me ei leia siit viiteid kunstniku emotsionaalsele seisundile, kontrollimatutele tundepuhangutele, mis võiksid olla põhjustatud jumalikust inspiratsioonist või üleloomulike vaimude kohalolust. Kõik baseerub inimese enese

31 Dieckmann, „Diderot’s Conception of Genius”, 152.

32 Kineret S. Jaffe, "The Concept of Genius: Its Changing Role in Eighteenth-Century French Aesthetics", Journal of the History of Ideas, vol. 41, 4 (1980), 587.

'en demande pardon aux genies, aux createurs; mais tout leur merite se borne a observer, trouver, et imiter. Ce n'est qu'en observant et qu'en imitant qu'on a invente.

Jean le Rond d'Alembert, „Discours preliminaire des editeurs”, Encyclopédie ou Dictionnaire Raisonné des Sciences, des Arts et des Métiers, Par une Société de Gens de Lettres (Paris, 1751), vol. 1, xi. La Poessie qui vient apres la Peinture er la Sculpture, ¿ qui n'employé pour l' imitation que les mots représente d'une manière vive du touchante les objets qui composent cet Univers, o som sens, elle lui

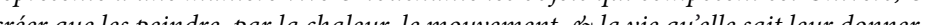

ümbritseva universaalse maailma tajumisel ja aistingutel, mida väljendatakse "loomiselaadsena“ kunstis.

Kujutlusvõimest (imagination) saab ajastu filosoofilise mõtte kesksemaid mõisteid, mille definitsiooni pakub oma entsüklopeedias välja Voltaire, kes jagab kujutlusvõime passiivseks ja aktiivseks, elutuks ja elavaks. Esimene neist säilitab mälus tahtevabalt hulganisti kujutisi, andmata neile kindlat vormi või sisu. Teine aga on võimeline korrastama ja kujundama materjali mälu kaudu esitatu läbi, kombineerides neist lõpmatult mitmekesise kujutiste rea, mis võib näida loomisena ning just seda „,väärtuslik kingitus“, mis „,̈hele sajast“ antud, ongi jumalikku päritolu geenius ${ }^{34}$ „Aktiivne kujutlusvõime on see, mis ühendab järelemõtlemise ja ideede kombineerimise mäluga; ta lähendab paljusid üksteisele kaugeid asju, ta lahutab neid, mis on segunenud, ta paneb asju teisiti kokku ja muudab neid; ta näib loovat, ehkki tegelikkuses ta vaid seab ümber, kuna inimesele ei ole antud võimet ideid luua, ta võib neid üksnes modifitseerida. Aktiivne kujutlusvõime on tegelikult meist endist niisama sõltumatu võime, nagu seda on passiivne kujutlusvõimegi, ning seda, et ta meist ei sõltu, tõendab järgmine katse: paluge sajal ühtmoodi teadmatul isikul kujutada ette mõnda uut masinat ja veendute, et üheksakümmend üheksa neist ei suuda kõigist jõupingutustest hoolimata midagi sellist ette kujutada. Kui aga sajas siiski midagi kujutleb, kas pole siis ilmselge, et tegemist on talle osaks saanud erilise kingituse või andega? Just seda andi kutsutaksegi „geeniuseks“ ja selles tunneme ära midagi, mis on inspireeritud ja jumalik.“35

Nii toob Voltaire tagasi irratsionaalse kunstnik-geeniuse, kelle võib endas ära tunda passiivse kujutlusvõimega inimene, kes laseb end „sütitavail ja kirglikel“ kujutlustel hulluseni viia. Just seepärast nõuab aktiivne kujutlusvõime alati enda kõrvale otsustusvõimet. Jean-François de Saint-Lambert, kellele enamus käsitlusi omistavad „Geeniuse“ artikli

34 17. sajandi käsitlustes on kujutlusvõime kui nähtus olnud ohjamist vajav, reegleid eirama kutsuv ning ohtlik tundesuurus. Voltaire kujutab seda ühe esimesena kui geeniuse peamist liikumapanevat võimet.

35 Encyclopedie, ou Dictionnaire Raisonne des Sciences, des Arts et des Metiers, Par une Societe de Gens de Lettres (Paris, 1765), vol. 8, 561.

L'imagination acitve est celle qui joint la réflexion, la combinaison à la mémoire; elle rapproche plusieur objets distans, elle sépare ceux qui se mêlent les compose \&u les change; elle semble créer quand elle ne sait qu'arranger, car il n'est pas donné à l'homme de fe faire des idées, il ne peut que les modifier. Cette imagination active est done au fond une faculte aussi independante de nous que l'imagination passive \& une preuve quelle ne depend pas de nous, c'est que si vous proposez a cent personnes egalement ignorantes d' imaginer telle machine nouvelle, il y en aura quatre-vingt-dix-neuf qui n' imagineront rien

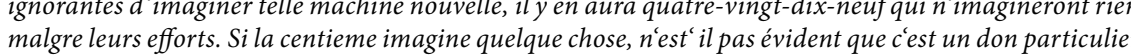
quelle a reçu? 'ést ce don que l'on appelle génie; c'est-là qu'on a reconnu quelque chose d'inspiré $\mho \mho$ de divin. 
autorsuse „Entsüklopeedias”, defineerib lakooniliselt: „Avar vaim, tugev kujutlusvõime ja ergas hing - see ongi geenius. ${ }^{136}$ Geenius on lõplikult muutunud konkreetseks isikuks: ta on, mitte ei oma seda omadust ega ka ei saa seda omandada ja arendada. Ja see geenius on läbi-lõhki „tundegeenius“: „Geenius, kes on ümbritsetud teda paeluvatest objektidest, unustab enda ja näeb ainult neid; oma kabineti vaikuses ja hämaruses naudib ta seda rõõmsat ja viljakat maastikku; ta tunneb jahedaid tuuleiile või kõrvetavat päikest; ta kardab tormi. Tema kujutlusvõime andub kõigele sellele, mis võib neid elamusi suurendada; ta tahaks mitmesuguste värvide ja kindlate joonte abil anda keha neile vaimukujudele, kes on tema enda loodud, kes teda mujale kannavad ja lõbustavad. “37 Kui Voltaire oma artiklis annab lugejale kõigiti teada Kõrgema Olendi (l’Etre supreme) kohalolust, siis Saint-Lambert'i jaoks tegutseb kunstnik oma tahte järgi, hetke ajel, isiklikest impulssidest lähtudes.

Näib, et Saint-Lambert' nägemises on tõelise geenius-kunstniku pärisosaks subliimsuse ja ekstaasi tunne. „Entusiasmi palangus ei märka ta loodust ega oma järjekindlaid mõtteid; ta on kandunud olukorda, milles viibivad tegelaskujud, keda ta ise toimima paneb; ta on võtnud enesele nende iseloomu, ja kui ta tunneb kõige kõrgemal tasandil kangelaslikke kirgi - näiteks õilsa hinge kindlameelsust, kes on oma jõudu tundes igast ohust üle, või isamaa-armastust, mis võib viia eneseunustuseni -, siis teostab ta ülevust /---/." ${ }^{\text {"3 }}$

Denis Diderot dialektilises esteetikanägemises kõneleb samaaegselt kirjanik ja filosoof. Ta soovis jagada neid tähelepanekuid, mis ilmnesid kunstnikus puhtfüüsiliselt kunstiteose valmimise protsessis, samas

36 Encyclopedie, ou Dictionnaire Raisonne des Sciences, des Arts et des Metiers, Par une Societe de Gens de Lettres (Paris, 1782), vol. 15, 943.

L'etendue de l'esprit, la force de l'imagination, \& l'activite de l'ame, voila le genie.

L'etendue de 37 Ibidem.

Le genié entouré des objets dont il s'occupe, ne sa souvient pas, il voit; il le silence \& l'obscurité du cabinet, il jouit de cette campagne riante es féconde; il est glacé par le sifflement des vents; il est brule par le soleil; il est effrayé des tempêtes. /---/ elle se livre a tout ce qui peut l'augmenter; elle voudroit par des couleurs varies, par des truits ineffaçables, donner un corps aux fantômes qui sont son ouvrage, qui a transportent ou qui l'amusment.

38 Ibidem.

---/ dans la chaleur de l'enthousiasme, il ne dispose ni de la nature ni de la suite de ses idées, il est transporté dans la situation des personnages qu'il fait agir; il a pris leur caractére: s'il eprouve dan le plus haut degré les passions héroïques, telles que la confidance d'une grande âme que la sentiment de ses forces éève au dessus de tout danger, telle que l'amour de la patrie porté jusqu'a l'oubli de soi même, il produit la sublime, le moi de Médée, la qu'il mourut du vieil Horace, le je suis consul de Rome de Brutus: transporté par d'autres passions, il fait dire à Hermoine, qui te l'a dit? à Orosmane, j'étais
aimé aime; à Thieste, je reconnois mon frere. soovides säilitada mõistusepäraseid, loogikast lähtuvaid teooriaid, mis olid valgustusaja filosoofia nurgakivideks. ${ }^{39}$

18. sajandi esteetilise mõtte vaieldamatuks suurkujuks tõusis entsüklopeedia väljaandja, filosoof, kirjandus- ja kunstiteoreetik Denis Diderot kelle mõtted väärivad tähelepanelikumal lugemisel meenutamist veel tänaste aktuaalsetesse kunstiküsimustesse süvenedes. Näitekunstist kirjutades väidab Diderot: „Karakteri tunnusjooned /---/ sünnivad inspiratsioonist - siis, kui suurvaimud looduse ja oma kavandi vahel viibides pööravad tähelepaneliku pilgu kord ühele, kord teisele. Ilu, mida nad säärastel inspiratsioonihetkedel loovad ja oma loomingusse üle kannavad, samuti ettenägematud jooned, mille äkiline ilmumine üllatab neid endidki, jätavad sügavama ja kestvama mulje kui see, mis on visandatud üksnes kujutlusvõime juhusliku kapriisi ajel. Külmaverelisus peab ülekeevat vaimustust vaos hoidma. Me ei kuuletu ju mingile pea kaotanud mürgeldajale, vaid see eesõigus kuulub inimesele, kes ennast valitseb." ${ }^{\prime 40}$

„Ainult tunded ja suured tunded on need, mis suudavad tõsta hinge suurte asjadeni.“41 "Filosoof arutleb, innustatu tunnetab. Filosoof on kaine, innustatu on joovastunud." (Le philosophe raisonne, l'enthousiaste sent. Le philosophe est sobre, l'enthousiaste est ivre). Kõigi vastuoksuste kiuste, mida tekitavad autoris mõistuse ja tunnete vahelises konflik tis kompromissi otsimine, mis selgelt mitmetes tekstides ka lugeja eest varjule ei jää, annab autor eelistuse tunnetele ning mis veelgi olulisem - kontrollimatutele tunnetele: „See inimene on looduse ülipeen jäljendaja, vaadake, mida ta oskab teha peitli, pliiatsi või pintsliga; imetlege tema hämmastavat teost; paraku, niipea kui ta oma ametialase tööriista käest ära paneb, on ta hull. Vaadake poeeti, keda näib inspireerivat tarkus ja kelle kirjutised on tulvil kuldsete tähtedega graveerimist väärt mõtteteri; hetk hiljem ei tea ta enam isegi, mida ta teeb ja räägib; ta on hull. Oraator, kes köidab me hingi ja vaime, kes käsutab neid oma tahtmist mööda, kaotab kõnetoolist alla laskudes igasuguse enesevalitsuse;

39 Jaffe, „The Concept of Genius: Its Changing Role in Eighteenth-Century French Aesthetics", 594 40 Denis Diderot, ,Näitleja paradoks", thk Mirjam Lepikult, Akadeemia, 11 (2006), 2361. Cependant il n'y a que les passions \& les grandes passions qui puissent elever l'ame aux grandes choses. 
ta on hull. Mis vahet siis on, ma karjataksin, geeniusel ja tavamõistusel, rahulikul inimesel ja kirgedest haaratul! ${ }^{\sim 42}$

Innustatuse väärtustamise kaudu jõuab Diderot kunstniku „,hulluseni“, mis on kaheldamatult ",kindaheitmine“ sajandi kehtivale mõttekaanonile. See eriline, vaid kunstnikule omane „hullus“ ei lähtu mitte psühhopatoloogilisest algest, vaid on laenatud Platoni jumalikkusest inspireeritud poeedist, kus jumaliku päritolu on Diderot asendanud kaasasündinud erakordse isikuomadusega. Diderot mugandab antiigist pärineva müüdi oma kaasajal areneva psühholoogiateadusega, nihutades seeläbi geeniuse mõistet sammu võrra lähemale selle 19. sajandi tähendusele. Kui Platoni poeet on võimeline komponeerima vaid jumaliku vaimu olemasolul, siis Diderot' kunstnik loob omaenese geeniusest inspireerituna, püüdes vähendada miinimumini irratsionaalsuse kohalolu. Geenius lakkab olemast efemeerne vaim, mis hõljub oma omaniku kohal, vaid muutub nüüd erakordse kunstniku peamiseks töövahendiks, mis teeb temast selle, kes ta on. ${ }^{43}$ Samaaegselt kaasneb sellega paratamatult geeniuse ja tema teose kaugenemine kõigest tavalisest, samuti tema sisemise ekstraordinaarsuse mittemõistmine „tavavaataja“ poolt: „Nii mõnigi kord mõistus tasandab tundelisuse poolt tehtud kiiret hinnangut, astudes sellele vastu. Seepärast ongi mitmed kiiruga kiidetud teosed sama kiiresti ka unustatud. On aga mitmeid teisi teoseid, mida me pole märganud või ära põlanud, mis aja möödudes edenevad oma vaimsuselt ja tundelisuselt ning lähemal ja põhjalikumal vaatlusel saavutavad oma tegeliku, tõese väärtuse. Selline ongi iga geeniuse teose ebakindel saatus. See on üksi. Seda võib väärtustada vaid kohese mõistmise läbi tema suhestumisest loodusega. Kes on aga võimeline hoomama seda suhet? Vaid teine geenius. ${ }^{\prime 44}$

Kui Voltaire'i „elav kujutlusvõime“ on „korrastav“ ja „näivalt loov“, siis Diderot kohaselt „,kujutlusvõime ei loo midagi, ta jäljendab, kompo-

42 Denis Diderot, „Fragment du Salon de 1767, Vernet“, Recherches sur Diderot et sur l'Encyclopedie, 2 (1987), 100.

Celui ci est un imitateur sublime de nature, voyez ce quil sait exécuter soit avec l'ebauchoir, soit avec le crayon, soit avec le pinceau; admirez son ouvrage étonnant; eh bien, il na pas sitót déposél instrument de son metier quil est fou. Ce poète que la sagesse paroit inspirer et dont les ecrits sont remplis de sentences a graver en lettres dor; dans un instant il ne scait plus ce quil dit, ce quil fait, il est fou, cet

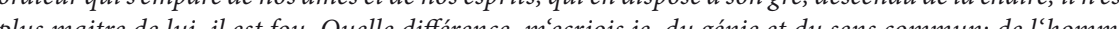
plus maitre de lui, il est fou. Quelle différence, mecriois je, du génie et du sens commun; de l'homme Pranquille et de homme passionne.

(1) 44 Art in Theory, 617 neerib, kombineerib, liialdab, suurendab ja kahandab." (L'imagination ne cree rien, elle imite, elle compose, combine, exagere, agrandit, rapetisse.) Siiski käsitleb ta seda kui võimet, mis kaotab piiri olemasoleva reaalsuse ja kunstilise nägemuse vahel. Olgu see nägemus, kas tõeline looming võ liialdatud jäljendamine, ta on võimeline kütkestama seda loonud inimest sedavõrd, et ta kaotab sideme olemasoleva maailmaga. Oma erakordse „hulluses“, mis ei ole mõistetav kujutlusvõimet mitteomavale isikule, on tema nägemus nii mõjus, et inspiratsioonist haaratud kunstnik pole võimeline seda adekvaatselt ära seletama. Inspireeritud inimene ei tea alati ka ise, kas see, mida ta kuulutab, on reaalsus või viirastus, kas see eksisteerib alati väljaspool teda ennast. Ta on siis inimloomuse energia viimsel piiril ja kunsti võimaluste tipul. ${ }^{45}$

Looduse jäljendamine, mis oli sajandeid kunstiteose olemuslikuks nurgakiviks ja kunstniku peamiseks eesmärgiks, on nüüd asetatud tahaplaanile ja esile kerkib kunstniku kui looja tegelaskuju loovuse algallikate otsimine. Ehkki me ei leia Diderot'lt otseseid viiteid kunstnikule kui loojale, on ta siiski mitmete mõistete (entusiasm, kujutlusvõime jne) laht seletamisel veendunud, et kunstnik-geeniust on võimatu vaadelda muul viisil kui „loojana“. Nii astub Diderot värsketele jälgedele, tema mõttearendustes võib kohata laene mitmetelt varasematelt kirjutajatelt, nagu Du Bos ja eriti oma ajastu üheks moeautoriks tõusnud Edmund Burke (,A Philosophical Enquiry into the Origin of Our Ideas of the Sublime and Beautiful“, 1757), kellelt Diderot on saanud otseseid mõttelaene oma „1767. aasta Salongis“ ilmunud kirjutise „üleva“ idee kirjeldamiseks. ${ }^{46}$

\section{LÕPETUSEKS}

Herbert Dieckmann on väitnud, et kogu geeniuse mõiste ajalugu näitab, et eksisteerib loomuomane suhe teooria vahel, mis käsitleb kujutlusvõimet üksnes kunsti vormilisuse tarvis vajaminevana ning sõna "geenius" on kasutatud vaid pelgalt ilustavas tähenduses, vaieldes koheselt sellisele pinnapealsele vaatenurgale vastu ja näidates, et tegu on enamaga - nimelt üksikisiku loova väljendusvõime väärtustamise ja geeniuse

45 Kineret Jaffe, „The Concept of Genius: Its Changing Role in Eighteenth-Century French Aesthetics", 598.

L'inspiré est lui-même incertain quelquefois si la chose qu'il annonce est une réalité ou une chimère, si elle exista jamais hors de lui. Il est alors sur la dernière limite de l'énergie de la nature de l'homme et

46 Gita May, Diderot and Burke: A Study in Aesthetic Affinity", PMLA, vol. 75, 5 (1960), 527-539. 
mõiste omavahelise seotusega. ${ }^{47}$ Jätkaksin eelnevat mõttekäiku - geeniuse arenemise kaudu ilmutab end Autor, geeniusele omistatud omaduste kaudu on võimalik identifitseerida ajas järjest eneseküllastunumaks muutuvat kunstnikku, kelle lõpp-pretensiooniks on mitte vähemat kui demiurgiks olemine. Kes võidab kõige enam 18. sajandi alguses tõstatatud huvist geeniuse kui nähtuse vastu, mis toimub käsikäes esteetikateooria tärkamisega? Vaieldamatult kunstnik ja tema teos. Sammhaaval kujundab kunstiteooria, mille utreeritud täiusekehastuseks kunstnik ju on, le belle nature jäljendajast selle täiustaja ja seejärel selle hülgaja unikaalse ja originaalse kunstitõe kasuks. Käesolevas artiklis käsitletud ajavahemik kujutab enesest selle protsessi esimest n-ö embrüonaalset staadiumi, mil kujundatakse välja teoreetiliste tõekspidamiste summa mis saab platvormiks edasistele muutustele kunstnik-geeniuse kujunemisel. 17. sajand annab meile „õppinud geeniuse“ talendika tegelaskuju, kes toetudes mõistuslikule, reeglitega seatud harmooniale, antiigitraditsiooni kaudu ainelise looduse ilutäiuse otsinguile ning didaktilisele väärikusele, kergitades maalikunstniku kaunite kunstide nobiliteedi hulka. Valgustussajandi püüd leida ratsionaalset ja mõistusele rajanevat seletust kunstniku olemusele ning toimimisele, loob aga paradoksaalsel kombel sajandi keskpaigaks hoopis teistlaadse kunstniku tüpaaži, sünnipäraste eriliste võimetega "hullunud geeniuse“, kes innustatuse leiutuslikkuse ja eelkõige inspiratsiooni ning kujutlusvõime ainukordse võime rakendamise läbi hakkab kujutama enesest irratsionaalset, spontaanset ja kontrollimatut subjekti, kes nüüdsest alates kindlasti pigem vastandub kui sobitub soovitavatesse raamidesse.

47 Dieckmann, „Diderot's Conception of Genius“, 154.
Holger Rajavee: Two Geniuses. From Lomazzo To Diderot Keywords: Genius; Mannerism; Classicism; la belle nature; FUROR POETICUS; ARTISTIC CREATION

SUMMARY:

the goal of the article is to examine the theoretical and aesthetical views related to art and concerning painters, mainly in the French tradition, from the early $17^{\text {th }}$ to the mid- $18^{\text {th }}$ century, starting with works by Gian Paolo Lomazzo and ending with the viewpoints of Denis Diderot. Using different examples from the texts of the key authors of their day, the article's aim is to show how, starting in the early $17^{\text {th }}$ century, the type of painter who can be described as a "learned genius" starts to develop and from the beginning of the next, $18^{\text {th }}$ century, this type gradually starts to transform into the subject that can be called a "mad genius" with all the main features of a modern artist.

With the introduction of the neo-Platonic Mannerist doctrine of Lomazzo and Federico Zuccari the "learned genius" is now in its embryonic stage of development, differing greatly from the Renaissance painters of an earlier era. The "painter-mystic" is a self-centred person, whose "inner eye" is directly connected through contemplation with the Divine. In the middle of the $17^{\text {th }}$ century, Charles Alphonse du Fresnoy, and especially Giovanni Pietro Bellori, by synthesizing Platonic and Aristotelian ideas, introduce us to the painter who possesses genius. He is freed from Mannerist mysticism and his main goal is to improve the imperfect Nature created by God through mind and reason. And to produce the perfect version of it in art - la belle nature - to achieve the result the artist has constantly developed himself - to learn and observe. The neo-classicist doctrine gradually burdens the genius with certain strict rules to follow; a process that is referred to here as "taming the genius". So by the end of the $17^{\text {th }}$ century, it is possible to talk about the "learned (but tamed) genius" - a noble, well-taught, reasonable and aesthetically high-minded artist.

At the beginning of $18^{\text {th }}$ century changes start occurring in the theoretical art paradigm, starting with Jean-Baptiste Du Bos and his Reflexions critiques sur la poësie et sur la peinture, written in 1719. This marks a new beginning in the development of the painter-genius figure and undoubtedly has significant influence on the writings that will follow on same subject. Du Bos starts to depart from the "reason-centred" painter, empha- 
sizing the moment of sensory perception as the main criteria in the art of painting. There are two main differences from earlier times. Firstly, the author is now talking about a person who already is genius rather than possessing genius, as was the understanding earlier. Secondly, the person is already born a genius, which means that this quality is no longer taught. There aren't any strict rules to harass the individual inventiveness and creativity of the artist.

In the middle of $18^{\text {th }}$ century many theoreticians, such as Jean le Rond d'Alembert, Etienne de Condillac, Voltaire etc, emphasized such important and very individualistic qualities of the painter as inventiveness, imagination, originality, enthusiasm. And they started to connect these to the centuries-old Platonic idea of poetic fury - furor poeticus - a state of mind in which the artist is almost maddened, insane and fully spontaneous while creating art. Denis Diderot is the first author who says outright that a painter-genius "is mad" (qu'il est fou) and in doing so summons up the ideas of his predecessors.

One could say that the different qualities mentioned above have guided the theoretical art narrative to the point where we can talk about the "mad genius", who is recognized as the creator of art and this is the point where the modern painter-genius, whom we know today, comes to life.

CV:

Holger Rajavee (b. 1969) is an external PhD candidate in University of Tartu's Department of Art History. He graduated from the University of Tartu in 1996 in art history, as has worked from 1996 to 2005 as a research fellow at the Tartu Art Museum. He is currently working at the University of Tartu's Viljandi Culture Academy and the Estonian Academy of Music and Theatre as a lecturer on art and cultural history. He has published articles on art criticism and theory, and curated numerous exhibitions. In his $\mathrm{PhD}$ thesis, he deals with philosophical and theoretical problems related to art that are associated primarily with aesthetics and the development of the artist persona more generally. 